\title{
Small hydropower development in Tibet: Insights from a survey in Nagqu Prefecture
}

\author{
Mingyue Pang ${ }^{\mathrm{a}}$, Lixiao Zhang, ${ }^{\mathrm{a}, *}$, AbuBakr S. Bahaj ${ }^{\mathrm{b}}$, Kaipeng Xuc $\mathrm{Xu}^{\mathrm{c}}$, Yan $\mathrm{Hao}^{\mathrm{a}}$, Changbo Wanga, d \\ ${ }^{a}$ State Key Joint Laboratory of Environmental Simulation and Pollution Control, School of Environment, Beijing Normal University, Beijing 100875, China \\ ${ }^{\mathrm{b}}$ Energy and Climate Change Division, Sustainable Energy Research Group, Faculty of Engineering \& Environment, University of Southampton, Southampton SO17 1BJ, UK \\ ${ }^{c}$ Chinese Academy for Environmental Planning, Beijing 100012, China \\ ${ }^{\mathrm{d}}$ Nanjing Research Institute for Agricultural Mechanization, Ministry of Agriculture, Nanjing 210014, China
}

\section{A R T I C L E I N F O}

\section{Keywords}

Small hydropower

Rural electrification

Sustainability

Tibet

\begin{abstract}
A B S T R A C T
Due to its large hydraulic power potential, Tibet has been proposed as the main hydropower development base in China after 2020. This is likely to result in the construction of large and medium sized hydropower projects in this region. To date, small hydropower (SHP) has played an essential role in rural electrification in Tibet. Here we present a review of the status of SHP plants in Tibet and explore its potential based on a field survey conducted in the summer of 2014 in Nagqu Prefecture. The survey revealed that SHP in Nagqu has made it possible for approximately 80,000 local residents ( $16.3 \%$ of the total population) to have access to electricity. Our study shows that SHP suffers from problems such as low utilization of the installed power capacity, high scrap ratio, and has severe impacts on the local ecosystem. Moreover, the role of SHP in Tibet's rural electrification is gradually changing with the arrival of the main power grid, which has also impacted existing SHP plants. In order to improve SHP overall sustainability, optimization of existing plants and construction of new plants with higher standards are deemed necessary. This has to be done with due consideration to the fragile ecosystem in Tibet. Therefore, any expansion in the development of SHP in Tibet should have an appropriate strategy for sustainability and ecosystems conservation and protection.
\end{abstract}

\section{Introduction}

China possesses rich small hydropower $(\mathrm{SHP})^{1}$ resources, with a technically exploitable capacity of $128 \mathrm{GW}$ [1-3]. Promoted by abundant resources and a series of government incentives, SHP has seen soaring growth since the founding of the People's Republic of China in 1949 (see Fig. 1). Such growth can be divided into three stages $[4,5]$. Initially, SHP was developed for rural electrification because of its advantages, which include mature technology, easy maintenance, and financial competitiveness [6,7]. However, as early as the beginning of the 1980s, SHP became an important industrial development option to accelerate the growth of the rural economy in addition to satisfying the local electricity demand $[8,9]$. Small hydropower is regarded as a promising renewable energy source that has the potential to address the increasing pressures of energy security and carbon emission abatement; and hence has been assigned ambitious development goals in recent years [10-12]. By the end of 2015, there were more than 47,000 SHP plants in China with an aggre- gate installed capacity of $75.83 \mathrm{GW}$. Such plants provide electricity to approximately 300 million rural residents in $1 / 3$ of the counties and $50 \%$ of Chinese territories. With an annual output of 235.13 TWh, SHP has become an important fraction of hydropower generation in China, accounting for approximately $21 \%$ of the total annual hydropower output $[13,14]$.

With an average elevation of $4000 \mathrm{~m}$ above sea level, Tibet is recognized as the "roof of the world" and the "third pole of the world". Owing to its elevation, Tibet has the largest concentration of glaciers outside of the polar caps. As the main part of the eastern Himalayan region, Tibet is the point of origin of several major Asian rivers and countless small streams and is therefore referred to as the "water tower of Asia" $[15,16]$. The technically feasible potential of hydropower in the region is estimated to be $110 \mathrm{GW}$, of which $9.05 \mathrm{GW}$ is SHP, ranking third among the Chinese provinces. With regard to SHP development in Tibet, only $0.3 \mathrm{GW}$ was exploited by the end of 2015. Generally, its development is relatively slow and variable, as illustrated in Fig. 2 [9,13]. Nevertheless, SHP, as an essential component of public welfare, has played an essential role in providing electricity to local residents in off-

\footnotetext{
* Corresponding author.

Email addresses: pangmingyue@mail.bnu.edu.cn (M. Pang); zhanglixiao@bnu.edu.cn (L. Zhang); A.S.Bahaj@soton.ac.uk (A.S. Bahaj); xukp@caep.org.cn (K. Xu); haoyan@bnu.edu.cn (Y. Hao); changbo@mail.bnu.edu.cn (C. Wang)

URL: http://www.energy.soton.ac.uk
} 
grid areas of Tibet. According to published data, by the end of 2010, approximately 0.9 million local residents in 56 counties had access to electricity because of SHP development [17].

Like other Himalayan countries, to convert the "water tower" into "power tower" [18], the Chinese government has proposed Tibet as the main hydropower development base after 2020. Such development is geared to sustain its rapid economic growth and diversify its energy infrastructure. An increasing number of medium and large hydropower projects can be expected in Tibet following construction of the Zangmu Hydropower Station $[19,20]$. In this context, the role of SHP, as well as its development strategy and its regional impacts will need to be investigated to establish indicative and appropriate pathways for its growth. There has been some published review papers which were associated with SHP development in China and other Himalayan regions $[4,9,18]$. However, comprehensive surveys and reviews of SHP have not been conducted for Tibet. The exception is a case study analysis which emphasised that SHP schemes in Tibet will induce greater stress on local ecosystems when compared with their counterparts in Guizhou Province in China [21]. Indeed, the belief that SHP systems are a source of safe energy with few or no ecological problems is questionable, especially in areas that have a fragile alpine ecosystem, such as Tibet $[14,21,22]$.

Accordingly, there is an urgent need to investigate the status of SHP development in Tibet and the corresponding challenges associated with such development. To address this, a field survey of SHP plants deployed in Nagqu Prefecture, northern Tibet was conducted in the summer of 2014. Our investigation was designed to: (1) establish the practical operational status of SHP plants in Nagqu Prefecture; (2) appraise existing problems that challenge sustainable development of SHP in Tibet; (3) provide policy recommendations for targets as well as a realistic roadmap of SHP development in Tibet; and (4) present a clear understanding any ecological concerns related to the deployment of SHP in Tibet.

\section{Methodology}

Massive local investigations and interviews were conducted to collect the qualitative and quantitative data of SHP development in Nagqu Prefecture. All the 27 SHP plants in Nagqu were visited in the summer of 2014. First, the SHP plants were observed to collect the basic information of the plants, including the location, scheme and installed capacity. Moreover, we recorded the main characteristics of local river and surrounding terrestrial ecosystems as well as obvious ecological impacts induced by the plants.

In addition to sites and plant observations, the officials of Bureau of Rural Electrification of each county in Nagqu Prefecture were interviewed to obtain the construction information of SHP plants, such as the sources of construction funds and the year of construction. Furthermore, in-depth interviews were conducted with the head manager of each SHP plant, which mainly focused on the operation and maintenance such as daily operational time, electricity price and breakdown maintenance. The surveys were augmented with detailed data (annual designed operational time and electricity generation) for all SHP plants obtained from plants design reports and confirmation by on-site interviews.

Finally, officials of the Water Resources Department of Tibet Autonomous Region were interviewed to obtain the actual annual electricity produced by each SHP plant in Nagqu Prefecture and the number of local residents served by them.

\footnotetext{
1 The definition of SHP differs from country to country and changes with the national economy and rural energy consumption. Currently in China, SHP refers to hydropower plants with an installed capacity of no more than 50 MW [3].
}

\section{Small hydropower in Nagqu Prefecture}

\subsection{Progress of SHP development in Nagqu Prefecture}

Nagqu Prefecture is located in the northern part of Tibet, in the hinterland of the Qinghai-Tibet Plateau. Covering a total area of 0.35 million $\mathrm{km}^{2}$ between the Tibetan Gangdise Mountains and the northern part of the Nyainqentanglha Range. Nagqu Prefecture consists of 11 counties and had a total population of 0.49 million at the end of 2012 (Fig. 3) [23]. This region is the riverhead of major Asian rivers, such as the Yangtze, Nujiang and Lancang rivers. Thus, Nagqu is extremely abundant in water resources [24]. Approximately $94.4 \%$ of the prefecture belongs to the alpine grassland ecosystem (alpine meadow, alpine steppe and alpine desert-steppe), which has been characterized as extremely fragile [24-26]. It should be noted that alpine grassland ecosystem is the main ecosystem type across Tibet [27].

Before the construction of SHP plants in Nagqu, local residents mainly relied on traditional biomass, such as cattle dung and firewood, for cooking and lighting for thousands of years [28-30]. Since the early 1990s, several SHP plants have been built around the urban areas of the counties to provide electricity for local residents. After implementation of the Chinese Grand Western Development Program (ca. 2000), more SHP plants to serve rural villages were constructed, further raising the rural electrification level. Since 2005, a new batch of SHP plants was constructed around the urban areas to overcome the failures of previous plants. Such failures can be classified as low capacities to satisfy demand and frequent plant failures due to old equipment or construction defects. Currently, approximately 80,000 local residents in Nagqu Prefecture (16.3\% of the total population) rely on SHP plants for their electricity supply [23]. Table 1 provides detailed information of all SHP plants in Nagqu Prefecture including the construction time, installed capacity, running time, and current status.

Our investigation confirmed that a total of 27 SHP plants were remaining on-site up in Nagqu Prefecture to 2014 (Fig. 3). Since more than $60 \%$ of the population is distributed in the eastern Nagqu region, including Nagqu, Lhari, Biru, Sog, and Baqen counties [23], most SHP plants were also constructed in these areas. The total installed capacity of the 27 SHP plants was $26.9 \mathrm{MW}$, and the average capacity is around $1 \mathrm{MW}$. It is important to note that no new plants were constructed in Nagqu since 2010.

\subsection{Characteristics of SHP development in Nagqu Prefecture}

The surveys conducted revealed that SHP development in Nagqu Prefecture is still in the primary stage, i.e., it is constructed for rural electrification as an important social service for local residents, rather than for promoting the rural economy or providing renewable energy for the country [31]. This is relatively backward compared with SHP development in the eastern provinces, such as Zhejiang and Guizhou [32-34]. Overall, the investigated SHP plants presented the following characteristics:

(1) The average installed capacity per plant is relatively small (1 MW) and is much lower than the average of the entire country (1.52 MW in 2013) [35]. As shown in Fig. 4, if these plants are further subdivided based on their installed capacity [36], mini plants (in the range of 0.1-2 MW) constitute the majority. Only 1 SHP plant was installed with a capacity of more than $2 \mathrm{MW}$, namely, the Chalong plant, which was designed to serve the urban area of Nagqu County (the administrative center of Nagqu Prefecture). The other two plants were categorized as micro plants (less than $0.1 \mathrm{MW}$ ) and were built to serve rural areas. Full details are in Table 1 and locations in Fig. 3.

(2) All SHP plants were isolated power grids and are not connected to the national grid network. Therefore, it is not possible to balance the demand and supply over a day or throughout the year by selling excess power back to or buying additional power from the national grid. Accordingly, wastage of the installed capacity and an unstable supply of electricity are inevitable. Moreover, im 


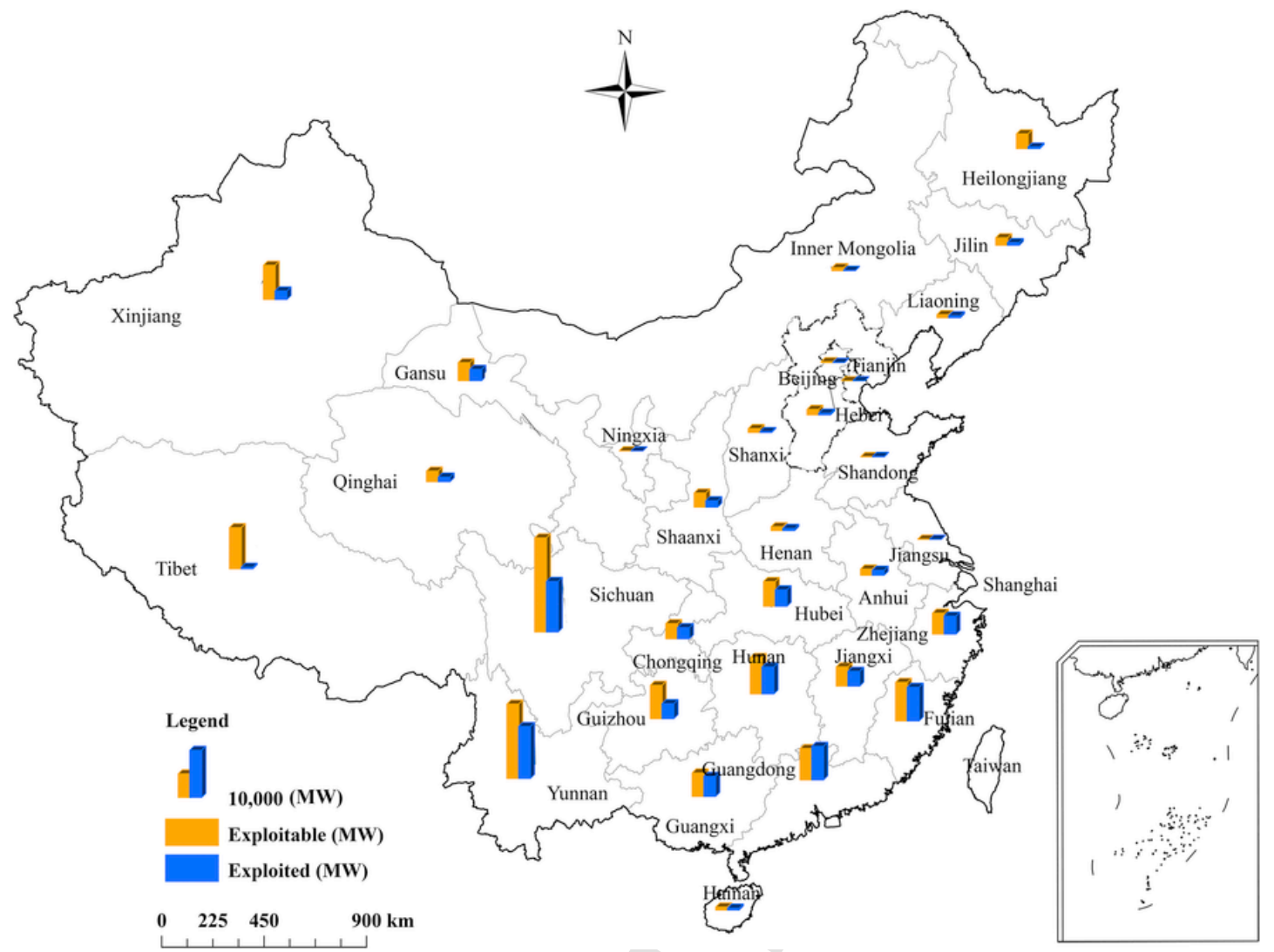

Fig. 1. Exploitable and exploited (in 2015) capacity of SHP in Chinese provinces. Data source $[9,13]$.

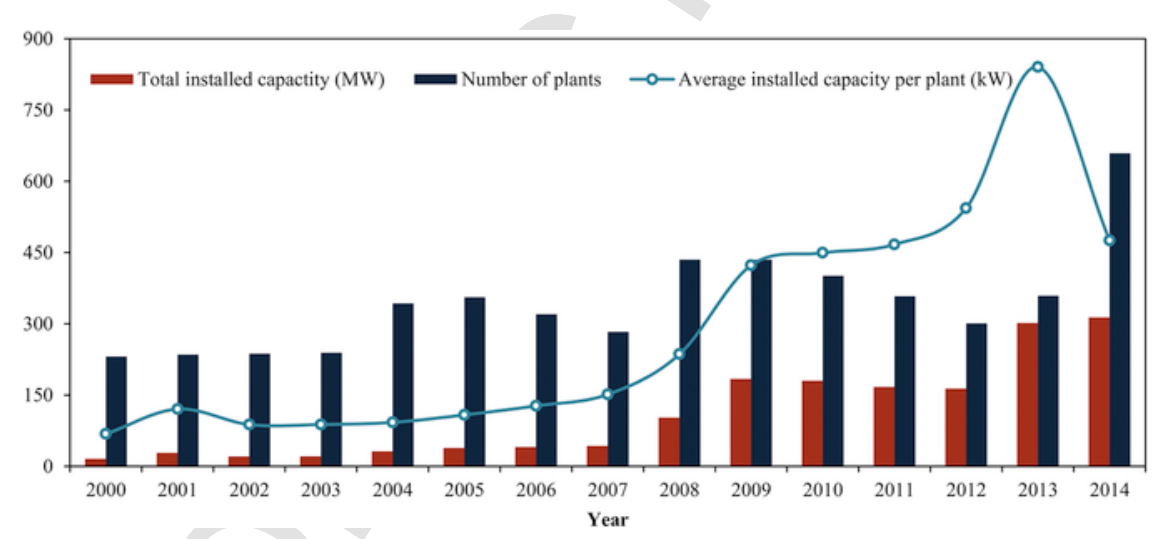

Fig. 2. SHP development in Tibet from 2000 to 2014. Data source [13].

consequences on the equipment, easily leading to a breakdown and reduction of its lifespan.

\subsection{Problems associated with SHP development in Nagqu Prefecture}

Although SHP in Nagqu Prefecture has achieved remarkable results in providing electricity access for local rural residents, some factors, such as the low utilization of installed capacity, high scrap ratio and evident disturbances to local ecosystems, have been noted in our surveys. These factors have influenced and restricted the sustainable development of SHP to a certain extent, not only in Nagqu, but throughout the Tibetan region.

(1) Low utilization of installed capacity: In 2013, the actual outputs of these plants were only $10-40 \%$ of their designed capacity (Table 1). This means that more than $60 \%$ of the installed capacity was wasted over the entire year. Among the various reasons for this, off-grid operation frequent shutdown were two major influencing factors. As mentioned above, these SHP plants are mainly running off-grid; therefore, they cannot operate to full capacity under the relatively low and unstable demand by local residents. There are abundant water resources available to sustain operation at capacity. The lack of anchor loads has led to wasted capacity and long periods of idle equipment and operation. The plants also suffered from frequent shutdowns due to equipment failures, during which time water resources flow directly through the plants without generating electricity. Relatively poor equipment as compared with plants in developed countries and the extensive operation are responsible for these frequent failure rates. In addition, except for simple maintenance, the equipment usually needs to be shipped to eastern provinces for repair due to the unavailability of parts, skills and related technology within Tibet. This is time consuming and directly affects the output of plants.

(2) High scrap ratio of constructed plants: Generally, the lifetime of an SHP plant is 35-50 years [37]. However, of the SHP plants that investi- 


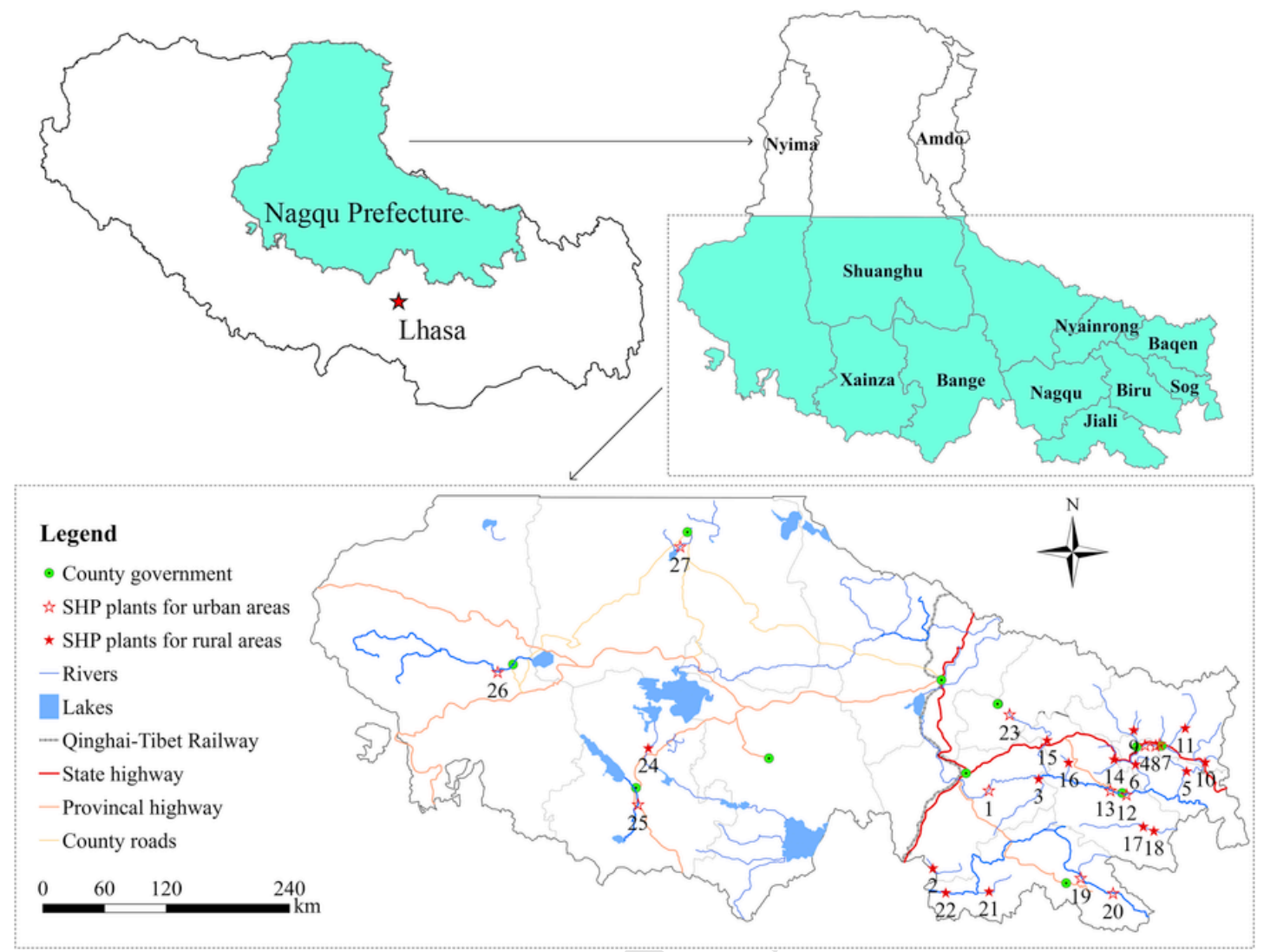

Fig. 3. Locations of the investigated SHP plants in the Nagqu Prefecture, Tibet. Note: The number of each plant corresponds to the number in Table 1.

Table 1

Detailed information of the SHP plants in Nagqu Prefecture, Tibet.

\begin{tabular}{|c|c|c|c|c|c|c|c|c|}
\hline Number & SHP plant & Location & $\begin{array}{l}\text { Completion } \\
\text { time }\end{array}$ & $\begin{array}{l}\text { Installed } \\
\text { capacity } \\
(\mathrm{MW})\end{array}$ & $\begin{array}{l}\text { Designed } \\
\text { operation } \\
\text { time }(\mathrm{h})\end{array}$ & $\begin{array}{l}\text { Actual operation } \\
\text { time in } 2013 \text { (h) }\end{array}$ & $\begin{array}{l}\text { Percent } \\
(\%)\end{array}$ & Status \\
\hline 1 & Chalong & Nagqu & 1996 & 10.8 & 4040 & - & - & Back-up \\
\hline 2 & Youqia & & 2003 & 0.15 & 5562 & - & - & Scrapped \\
\hline 3 & Nyima & & 2002 & 0.15 & $* *$ & - & - & Scrapped \\
\hline 4 & Suoxian & Sog & 2003 & 0.96 & 6633 & 2583 & 38.94 & Operation \\
\hline 5 & Gamei & & 2007 & 0.25 & 4320 & 1160 & 26.85 & Repaired \\
\hline 6 & Erong & & 2009 & 0.1 & 5531 & 600 & 10.85 & Operation \\
\hline 7 & Aerdan-first & Baqen & 1996 & 0.75 & 5067 & 667 & 13.16 & Operation \\
\hline 8 & $\begin{array}{l}\text { Aerdan- } \\
\text { second }\end{array}$ & & 2005 & 0.8 & 6916 & 1675 & 24.22 & Operation \\
\hline 9 & Gaokou & & 2004 & 0.15 & 5571 & 1400 & 25.13 & Operation \\
\hline 10 & Yaan & & 2005 & 0.2 & 6107 & 1400 & 22.92 & Operation \\
\hline 11 & Manta & & 2007 & 0.075 & 4676 & - & - & Scrapped \\
\hline 12 & Biru & Biru & 1990 & 1.6 & $* *$ & - & - & Scrapped \\
\hline 13 & Jiqian & & 2010 & 2 & 6533 & 1480 & 22.65 & Operation \\
\hline 14 & Zhala & & 2003 & 0.15 & $* *$ & - & - & Scrapped \\
\hline 15 & Xiaquka & & 2003 & 0.5 & $* *$ & - & - & Scrapped \\
\hline 16 & Datang & & 2004 & 0.125 & $* *$ & - & - & Scrapped \\
\hline 17 & Yangxiu & & 2005 & 0.2 & 5616 & 760 & 13.53 & Repaired \\
\hline 18 & Baiga & & 2010 & 0.5 & 5727 & 2046 & 35.73 & Operation \\
\hline 19 & Lhari-first & Lhari & 1996 & 0.75 & $* *$ & - & - & Scrapped \\
\hline 20 & $\begin{array}{l}\text { Lhari- } \\
\text { second }\end{array}$ & $>$ & 2008 & 1.5 & 4825 & 933 & 19.34 & Operation \\
\hline 21 & Cuoduo & & 2006 & 0.2 & 6132 & 860 & 14.02 & Operation \\
\hline 22 & Serong & & 2007 & 0.2 & 6200 & 1665 & 26.85 & Operation \\
\hline 23 & Nyainrong & Nyainrong & 1996 & 0.96 & $* *$ & - & - & Scrapped \\
\hline 24 & Xiongmei & Xainza & 2010 & 0.75 & 6595 & 1160 & 17.59 & Operation \\
\hline 25 & Jiagang & & 1998 & 1.5 & 7200 & 2867 & 39.82 & Operation \\
\hline 26 & Nyima & Nyima & 2010 & 1.26 & 5880 & $* *$ & $* *$ & Operation \\
\hline 27 & Xiyaer & Shuanghu & 2007 & 0.32 & 7300 & $* *$ & $* *$ & Operation \\
\hline Total & & & & 26.9 & & & & \\
\hline
\end{tabular}

** Not available because of missing data; --No data because the plant was scrapped. 
Number of plants in each class

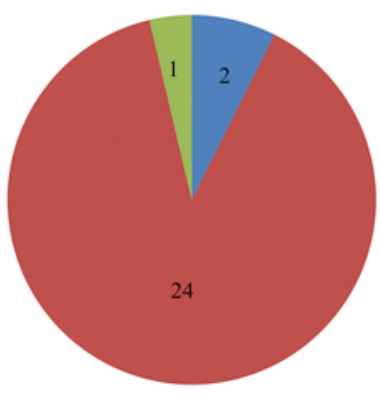

Installed capacity in each class (MW)

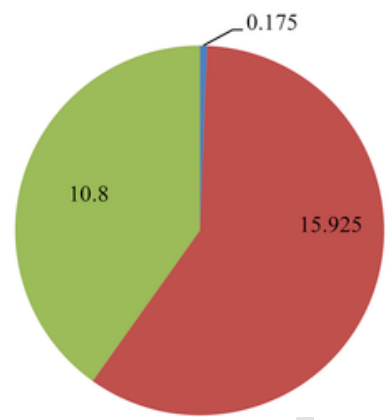

Fig. 4. Comparison of size of SHP plants in Nagqu Prefecture, Tibet.

gated, nine were completely scrapped prior to the end of their expected lifetime. The main reasons were construction defects, old equipment, or the accessibility to the power grid extension for the area they served. In fact, the operational times of some SHP plants, such as Xiaquka and Datang in Biru County, was not very long, with plants being less than 10 years old when scrapped. As shown in Fig. 2 , this problem is prevalent all over Tibet; an evident downward trend in both the total number of plants and the installed capacity was observed from 2009 to 2012 across Tibet. For instance, several SHP plants in Chamdo Prefecture of Tibet reportedly operated only for one year before they stopped functioning [8]. Undoubtedly, the scrapping of SHP plants in advance is a large waste of economic resources, especially in Tibet, where the construction costs are very high [38].

(3) Severe disturbance to local ecosystems: The alpine grassland ecosystem in Nagqu Prefecture, which is a result of the cold and dry climate, is very fragile and extremely sensitive to climate change and anthropogenic disturbances. This is also true of the glacier-fed river ecosystems in this region [39]. Once they are severely damaged, their recovery would be very slow or even impossible [25]. SHP development invariably includes a large amount of civil work which is required for plant construction and operation. The preparation of land is usually undertaken using explosives to facilitate construction and the subsequent building of plant components (e.g., dams or weirs, penstocks, and powerhouses). This inevitably causes massive disturbances to the sensitive permafrost environment in Nagqu [40-42]. During the operational stage, dam-toe-based SHP plants could trap a considerable amount of sediment in the reservoirs causing other ecological problems. Table 2 summarizes the main characteristics of the fragile alpine ecosystem and glacier-fed river ecosystem in Nagqu Prefecture, which is easily affected by SHP development according to the surveys conducted and confirmed by the literature $[22,24-27,43]$. During our field survey, it was clear that there were large disturbances to local ecosystems as a result of the SHP development. As can be seen in Fig. 5, substantial sediment was trapped by the Jiqian SHP plant in Biru County. Moreover, previous study quantitatively confirmed that SHP development in Tibet could lead to higher stress on the ecosystem than SHP development in other regions of China [21].
Table 2

Main characteristics of the fragile alpine ecosystem that is easily affected by SHP development in Nagqu Prefecture.

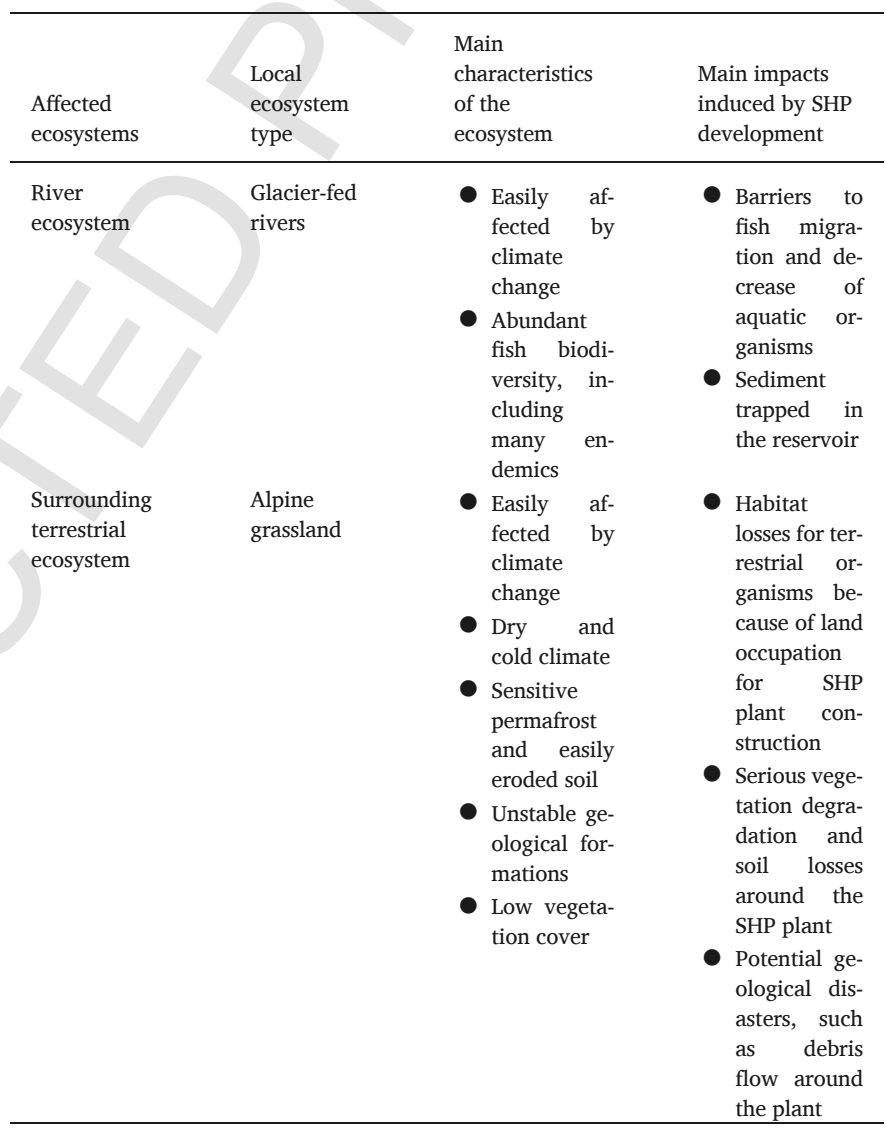

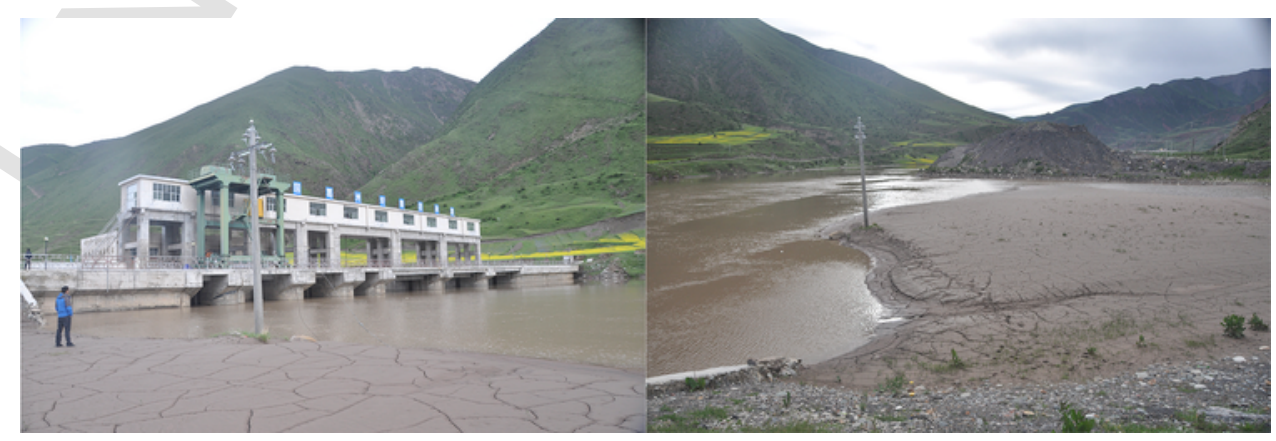

Fig. 5. Extensive sediment deposition in the reservoir of the Jiqian SHP plant in Biru County. 


\section{Challenges to SHP development in Nagqu Prefecture}

\subsection{Irrational planning and construction of SHP plants}

The planning of an SHP plant is a complex process, involving a series of rigorous stages, to determine the plant site, scale, and generating equipment $[37,44]$. However, the survey revealed that many SHP projects were subject to arbitrary decisions and irrational planning.

(1) The sites of some SHP plants were determined arbitrarily, without consideration of the landscape and an adequate reconnaissance survey. For example, the Xiaquka SHP plant in Biru County was constructed in a mountain gap, where the soil was washed extensively by the snow-melted water from the mountains during summer. As a result of substantial reservoir sedimentation, the plant only operated for 10 years before being scrapped. The Manta SHP plant in Baqen County stopped functioning due to similar issues.

(2) Unsuitable schemes were selected for some plants: According to the interviews with the plants head managers, SHP schemes (dam-toe, diversion, and hybrid scheme) in Tibet usually depended on the availability of financial support for construction, with little regard to the feasibility and potential ecological impacts of different SHP schemes [45]. For instance, it is not feasible to construct a dam-toe-based plant on the narrow river between two steep mountains, such as the Manta plant in Baqen, because it is difficult to clear the sediment trapped in the reservoir and the plant then has to stop running.

(3) Inappropriate installed capacity was selected for SHP plants: The surveys revealed that the installed capacities of most of the plants investigated were considerably in excess of the actual local electricity load available in their vicinity. If the equipment always operates at low power or is left idle, the lifespan of the equipment will be drastically shortened. Moreover, if the actual electricity loads are much smaller than the rated power of the generating capacity, the plant cannot operate efficiently, which is a common problem in Nagqu.

(4) Outdated generating equipment in poor condition was installed in some SHP plants: In many circumstances, second-hand equipment retired from eastern provinces were used for such plants to save money. Together with bad maintenance and isolated operation, frequent breakdown of the equipment is inevitable. When the equipment is transported to other provinces for repair, the plant has to stop operating for long periods of time denying access to rural communities. It is worth noting that the maintenance cost became very high owing to the specialized production of parts necessary for the old equipment. However, without such maintenance the plants would have to be scrapped.

In addition to a lack of technical competence, shortage of money is mainly responsible for the above-mentioned problems. Tibet is the most undeveloped province in western China, lacking in financial capacity and relying mainly on central government transfer payments. However, the funding for SHP projects from the central budget are usually conservative, necessitating that supporting funds be contributed by local authorities. If the local government cannot provide its share because of limited financial resources, the reduced investment makes it difficult to adequately conduct pre-project planning work and the purchase of advanced generating equipment.

\subsection{Poor management of SHP plants}

Fluctuations in real-time electricity load greatly affected the stable operation of off-grid SHP plants in Nagqu Prefecture. In such cases, diligent and delicate management is required, particularly for the normal operation and maintenance of the hydro-turbines. Generally, routine maintenance such as inspection, cleaning, tightening of nuts and bolts and general building work at suitable intervals is essential to minimize the risk of breakdown [6]. rectly responsible for the operation of the plants. In addition, two or three educated staff members would document the daily operation while also conducting some simple operation and breakdown maintenance. However, slightly complex breakdown maintenance could not be conducted by the plant workers themselves. For plants that served rural areas, the situation was worse. Due to their remote location and poor working conditions, appointed managers with a basic knowledge of SHP operation were unlikely to stay in the plants at all times. In fact, they were present on-site only occasionally. Moreover, the rest of the staff had low or no technical education and little knowledge regarding the SHP. Indeed, they only knew how to perform simple mechanical operations, such as switching equipment on or off. Once the equipment fails, the plants have to stop operating and wait for breakdown maintenance engineers. The following factors can explain the reasons for such poor management of SHP plants in Nagqu:

(1) Lack of skilled personnel for SHP plant management in Tibet. Because of the tough working environment in Tibet, it is difficult for these plants to attract and retain qualified personnel from outside the region [38]. Within Tibet, few trained personnel would agree to stay in the extremely remote mountainous areas of Tibet for a long time. For this reason, the managers have to employ less skilled local residents for the daily operation of plants.

(2) Lack of operational funds. The relatively small electricity consumption during the operation period does not provided adequate economic return for SHP plants in Nagqu. Thus, additional money is required to support normal operation. Currently, the operational funding from governments is limited, which results in poor maintenance and few skilled workers [46].

(3) Lack of incentives. Unlike enterprises in other areas of China, the SHP plants in Nagqu are owned and controlled by branches of local governments [32], and the management system is similar to that of a planned economy. In such an environment, it is difficult to incentivize managers to be completely responsible for operation of the plants, making poor management inevitable, which is in accordance with the observations during the survey.

\subsection{Grid construction in Nagqu Prefecture}

The construction of the main power grid in Tibet is ongoing, which will influence SHP development [47]. To date, Nagqu County has been covered by the Zangzhong power grid; due to this the existing SHP plants in Nagqu County are no longer essential for the local residents. The fate of three constructed SHP plants has undergone diverged course of actions. The Chalong SHP plant, which previously served mainly the urban area of the county, has become the backup electricity source for the Nagqu Railway Station on the Qinghai-Tibet Railway to ensure regular service in case the Zangzhong power grid breaks down, while the Nyima and Youqia SHP plants, which previously served rural areas, were scrapped. Communication with the managers of the Nagqu Electric Power Enterprise confirmed that many SHP plants on the Lhasa River underwent similar fate when Lhasa obtained access to the Zangzhong power grid. In addition to clarifying the fate of existing projects, construction of the state power grid has also affected, and will continue to impact further development of new SHP plants in Nagqu Prefecture, making it redundant as an electricity source. According to the 12th Five-Year Plan for Tibet released in 2011, more areas such as the urban areas of Biru, Sog and Lhari were slated for connection to the main power grid by the end of 2015 [19]. This could explain why there has been no new SHP capacity installed in Nagqu Prefecture since 2010.

\subsection{New emerging alternatives for rural electrification in Nagqu Prefecture}

In recent years, technical progress has diversified the alternatives for rural electrification in Tibet. For instance, household solar photovoltaic (PV) power systems have been greatly promoted in Tibet with recent special financial aid from the central government through implementation of the Brightness Project and the Golden Sun Pilot Project $[48,49]$. Household PV power is appropriate for the constant migration of local Tibetan herdsmen 
(see Fig. 6). However, due to its dependence on solar radiation and the effect of the variable weather in the region, its power availability is unpredictable. Moreover, PV systems currently rely heavily on government subsidies due to high capital cost including the need for storage batteries [49]. Additionally, the public is increasingly voicing concerns about pollution caused by discarded batteries [50], which is another environmental concern beyond the scope of this paper. Nevertheless, it is certain that such new solar technologies are well suited to the demand in the rural communities and are becoming alternatives or competitors to SHP in Nagqu and the entire Tibetan area.

\section{Recommendations for future SHP development in Tibet}

It is safe to say that the SHP development in Nagqu Prefecture is the epitome of the entire Tibetan region. Other prefectures in Tibet have experienced, or will experience, a similar process, making SHP unsustainable in the long term. Thus, it is important to retarget and adjust the SHP development strategy in Tibet to enable overall sustainability. Below, we provide several recommendations that based on the outcomes of field investigation and empirical analysis.

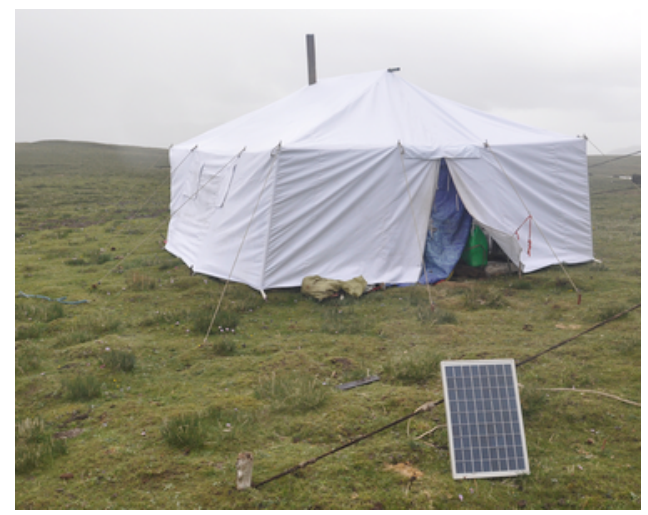

Fig. 6. Household photovoltaic power in Nagqu Prefecture, Tibet.
(1) Rigorous management of the existing SHP plants during the operation period is essential for their sustainability. There is a great need to foster specialized SHP personnel in Tibet, including both advanced management methods and personnel coupled with skill technicians and training of local cohort. This will undoubtedly improve the current state of the management and the plants operations. Communication and the exchange of personnel in other enterprises such as those in the eastern provinces is a good way of accomplishing this. Moreover, specialized technical schools within the autonomous region are needed to train more qualified technical personnel for SHP. Additionally, incentive mechanisms should be established to attract managers and skilled engineers to retain them to serve in the plants in full-time roles. Under the socialist market economy system, if operational rights are contracted to the managers or the entire staff, their enthusiasm might be stimulated. Then, the operation and maintenance of SHP plants would be improved, leading to less waste and higher monetary returns. Other advanced experiences, such as the 3-Self policy (i.e., self-construction, self-management and self-consumption) could also be introduced into SHP operation in Tibet [51].

(2) Faced with the gradual extension of the main power grid within Tibet, self-transition of existing SHP plants based on their environmental performance instead of direct scrapping is strongly recommended. As shown in Fig. 7, the Zangzhong power grid will cover most urban areas of the counties in Nagqu Prefecture by 2018 [47]. For those SHP plants with evident ecological problems, such as the Jiqian plant in Biru County, dismantling would be a good choice. However, for plants with relatively good environmental performance, directly scrapping them would be wasteful. If these plants can be connected to the grid and continue to operate, their economic performance would also be optimized since the facilities can be operated at full capacity. However, for these new grid-connected SHP plants, strict management during the operation period should be adopted to prevent over-exploitation of water resources since their outputs would not be limited by user consumption, resulting in adverse impacts on downstream river ecosystems like many SHP plants in Guizhou Province [14].

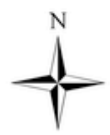

\section{Legend}

- Power plants

- Substation

- 110kV Zangzhong power grid in 2018

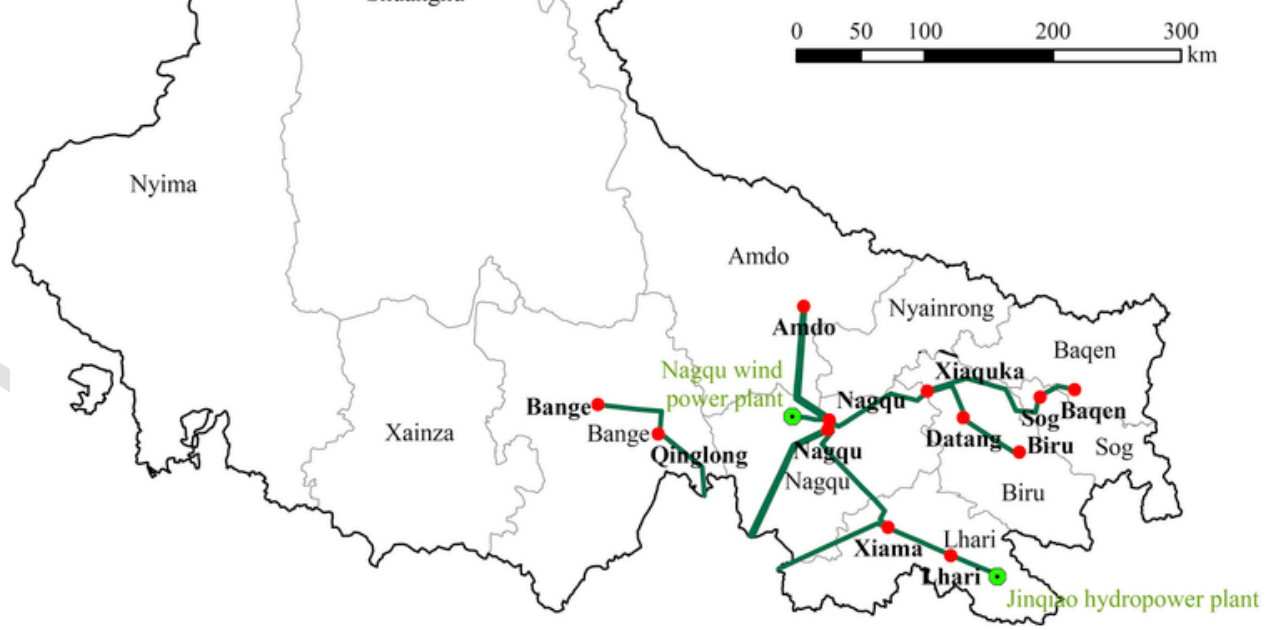

Fig. 7. Schematic of the planned $110 \mathrm{kV}$ Zangzhong power grid in Nagqu Prefecture in 2018. 
However, for relatively highly populated areas that will have no access to electricity in the near future, new SHP plants, especially mini and micro plants (less than $2 \mathrm{MW}$ ), will still be essential for economic growth and the social welfare of local residents. These plants will need sufficient construction funds and a smart design. Apart from receiving money from the government, encouraging enterprises to invest in SHP construction could also be considered $[52,53]$. Supported by sufficient funds, a smart design with rigorous reconnaissance surveys and pre-feasibility analysis will help determine the appropriate site and rational size of the plant. A diversion scheme is highly recommended considering its superior environmental performance than dam-toe and hybrid schemes [21]. Experienced construction crews and sophisticated equipment can also be made available to ensure engineering quality. In addition, advanced SHP technologies, especially those suitable for off-grid operation, should be developed and applied to promote a stable output of electricity supply to local residents in remote areas of Tibet.

(3) A conservation strategy should be adopted regarding further development of SHP in Tibet considering the importance of protecting the fragile alpine ecosystem. Apart from satisfying the electricity demand of rural communities in the off-grid areas, there will be the likelihood of constructing SHP plants for promotion of rural economic development with the gradual extension of the power grid, especially in water resource-rich and easy grid-connected areas. In other words, the role of SHP plants will change. However, the Tibetan government should avoid a blind rush to develop more SHP plants in this region without due to environmental impacts because both our field survey and evaluations showed that SHP plants in Tibet would cause severe disturbances to local ecosystems [21]. In areas where there is access to the national/state grid, new SHP plants with low installed capacities (e.g., less than $10 \mathrm{MW}$ ) are deemed unnecessary considering their high impacts on the local ecosystem. Although the government has an ambitious plan to exploit hydropower, a rigorous investigation and systematic evaluation of SHP plants is essential to understanding the ecological impacts caused by the massive intervention to local ecosystems as Tibet is very sensitive to global climate change, without stress due such interventions [54]. Indeed, development of hydropower should be conducted cautiously not only in Tibet, but throughout the entire Himalayan region, which is one of the current hotspots for SHP development [18].

\section{Concluding remarks}

As the epitome of Tibetan small hydropower (SHP) development, the practicality and future prospects of SHP development in Nagqu Prefecture were discussed in this paper in relation to observations and outcomes of field survey conducted in the summer of 2014. The survey revealed that SHP development in Nagqu is still at a preliminary stage to achieve the goal of impactful rural electrification. Though it has greatly improved the quality of life of local residents, irrational planning and poor management of SHP plants has led to low electricity output and high scrap ratio, as well as severe disturbances to local ecosystems. However, with the extension of the main power grid and the emergence of new alternatives to rural electrification, existing plants have undergone a changing role especially in Nagqu.

To promote sustainable SHP development in Tibet, several recommendations were proposed based on the outcomes of the field survey and further analysis, including (a) appropriate management, retention incentives, training of local personnel, (b) appropriate and orderly transition of existing SHP plants, (c) the provision of sufficient construction funds and a smart design for new SHP plants. We further emphasise the importance of minimizing local anthropogenic disturbances to the Tibetan already fragile ecosystem by exploring alternatives to reduce SHP construction in this area. Overall, Tibet should proceed with caution instead of a blind rush to the second and third stages of SHP development.

\section{Acknowledgements}

This work was supported by the National Science and Technology Major Project of the Ministry of Science and Technology of China (2017YFC0505703), Funds for International Cooperation and Exchanges of the National Natural Science Foundation of China (51661125010) and National Natural Science Foundation of China (41371521). We also acknowledge the support of the Energy and Climate Change Division and the Sustainable Energy Research Group (www.energy.soton.ac.uk) at the University of Southampton, were the first author spent time on a research during 2016.

\section{References}

[1] H.L. Huang, Z. Yan, Present situation and future prospect of hydropower in China, Renew Sustain Energy Rev 13 (6-7) (2009) 1652-1656.

[2] S. Zhou, X.L. Zhang, J.H. Liu, The trend of small hydropower development in China, Renew Energy 34 (4) (2009) 1078-1083.

[3] K.M. Kibler, D.D. Tullos, Cumulative biophysical impact of small and large hydropower development in Nu River, China, Water Resour Res 49 (2013) 3104-3118.

[4] Y.G. Kong, J. Wang, Z.G. Kong, F.R. Song, Z.Q. Liu, C.M. Wei, Small hydropower in China: The survey and sustainable future, Renew Sustain Energy Rev 48 (2015) 425-433.

[5] M. Zeng, S.J. Ouyang, H. Shi, Y.J. Ge, Q.Q. Qian, Overall review of distributed energy development in China: Status quo, barriers and solutions, Renew Sustain Energy Rev 50 (2015) 1226-1238.

[6] O. Paish, Small hydro power: technology and current status, Renew Sustain Energy Rev 6 (2002) 537-556.

[7] G.L. Luo, Y.W. Guo, Rural electrification in China: A policy and institutional analysis, Renew Sustain Energy Rev 23 (2013) 320-329.

[8] D.K. Xiao, Study on the development countermeasures of hydropower in east-Tibet, Chongqing University, Chongqing, 2010. [in Chinese].

[9] C.T. Cheng, B.X. Liu, K.W. Chau, G. Li, S.L. Liao, China's small hydropower and its dispatching management, Renew Sustain Energy Rev 42 (2015) 43-55.

[10] The National Development and Reform Committee, the People's Republic of China. The Medium- and Long-term Plan of Renewable Energy Source Development. Beijing (in Chinese); 2007.

[11] Z.X. Tian, New mission of small hydropower, Small Hydro Power 3 (2010) 8-9. [in Chinese].

[12] J. Zhang, C.Y. Luo, Z. Curtis, S.H. Deng, Y. Wu, Y.W. Li, Carbon dioxide emission accounting for small hydropower plants-A case study in southwest China, Renew Sustain Energy Rev 47 (2015) 755-761.

[13] National Bureau of Statistics of the People's Republic of China. China Statistical Yearbook 2016. Beijing: China Statistics Press (in Chinese); 2016.

[14] M.Y. Pang, L.X. Zhang, S. Ulgiati, C.B. Wang, Ecological impacts of small hydropower in China: Insights from an emergy analysis of a case plant, Energy Policy 76 (2015) 112-122.

[15] Q. Wang, Prevention of Tibetan eco-environmental degradation caused by traditional use of biomass, Renew Sustain Energy Rev 19 (2009) 2562-2570.

[16] T.D. Yao, L.G. Thompson, V. Mosbrugger, F. Zhang, Y.M. Ma, T.X. Luo, et al., Third pole environment (TPE), Environ Dev 3 (2012) 52-64.

[17] Y.S. Ji, Tibet made great achievement after the reform through continuous innovation in difficulties, China Water Power Electrification Z1 (2011) 103-107. [in Chinese].

[18] D. Kumar, S.S. Katoch, Harnessing 'water tower' into 'power tower': A small hydropower development study from an Indian prefecture in western Himalayas, Renew Sustain Energy Rev 39 (2014) 87-101.

[19] Tibet Autonomous Region Government. Tibet Autonomous Region 12th Five-Year Plan comprehensive energy development plan. Lhasa (in Chinese); 2011.

[20] S. Han, Zangmu hydropower station opened the "large hydropower era" of Tibet, Earth 4 (2015) 61-63. [in Chinese].

[21] L.X. Zhang, M.Y. Pang, C.B. Wang, S. Ulgiati, Environmental sustainability of small hydropower schemes in Tibet: An emergy-based comparative analysis, J Clean Prod 135 (2016) 97-104.

[22] T.H. Zhang, Emphasis of Tibet environmental protection with features of plateau environment, Environ Prot 1 (2000) 27-29. [in Chinese].

[23] Chinese Academy for Environmental Planning. Statistics data of Tibet Autonomous Region. Beijing (in Chinese); 2015

[24] Q.Z. Gao, Y. Li, Y.F. Wan, W.Z. Jiangcun, X.B. Qin, B.S. Wang, Significant achievements in protection and restoration of alpine grassland ecosystem in Northern Tibet, China, Restor Ecol 17 (4) (2009) 320-323.

[25] X.H. Zhong, S.Z. Liu, X.D. Wang, X.M. Li, Eco-environmental fragility and ecological security strategy in Tibet, J Mt Sci 21 (S1) (2003) 1-6. [in Chinese].

[26] Y.Y. Li, S.K. Dong, S.L. Liu, H.K. Zhou, Q.Z. Gao, G.M. Cao, et al., Seasonal changes of $\mathrm{CO}_{2}, \mathrm{CH}_{4}$ and $\mathrm{N}_{2} \mathrm{O}$ fluxes in different types of 
alpine grassland in the Qinghai-Tibetan Pleatau of China, Soil Biol Biochem 80 (2015) 306-314.

[27] Z.Y. Gao, Y.B. Wang, G.H. Liu, M.H. Liu, J. Luo, J.J. Yin, Response of soil moisture within the permafrost active layer to different alpine ecosystems, J Glaciol Geocry 36 (4) (2014) 1002-1010. [in Chinese].

[28] G.B. Zhang, Light of lighted plateau - the notes of Tibetan electricity construction, Electr Power 40 (11) (2007) 1-3. [in Chinese].

[29] G. Liu, M. Lucas, L. Shen, Rural household energy consumption and its impacts on eco-environment in Tibet: Taking Taktse county as an example, Renew Sustain Energy Rev 12 (7) (2008) 1890-1908.

[30] X.G. Ping, Z.G. Jiang, C.W. Li, Status and future perspectives of energy consumption and its ecological impacts in the Qinghai-Tibet region, Renew Sustain Energy Rev 15 (2011) 514-523.

[31] J. Chong, Strive to develop rural hydropower to improve the life quality of residents in the border minority areas, China Water Electrification 5 (2009) 12-13. [in Chinese].

[32] X.J. Chen, Z.Y. Wang, S.F. He, F.Q. Li, Programme management of world bank financed small hydropower development in Zhejiang Province in China, Renew Sustain Energy Rev 24 (2013) 21-31.

[33] T. Hennig, W.L. Wang, Y. Feng, X.K. Ou, D.M. He, Review of Yunnan's hydropower development. Comparing small and large hydropower projects regarding their environmental implications and socio-economic consequences, Renew Sustain Energy Rev 27 (2013) 585-595.

[34] L.X. Zhang, M.Y. Pang, C.B. Wang, Emergy analysis of a small hydropower plant in southwestern China, Ecol Indic 38 (2014) 81-88.

[35] Ministry of Water Resources, the People's Republic of China. China Water Statistical Yearbook 2013. Beijing: China Water Power Press (in Chinese); 2014.

[36] Liu H, Masera D, Esser L. World Small Hydropower Development Report 2013. United Nations Industrial Development Organization, International Center on Small Hydro Power; 2013.

[37] P. Adhikary, S. Kundu, Small hydropower project: standard practices, Int J Eng Sci Adv Technol 4 (2) (2014) 241-247.

[38] M.Q. Yang, C.L. Wang, The effect of climate and geography particularity in Tibet on the cost of hydropower project, Water Power 34 (6) (2008) 95-97. [in Chinese].

[39] W.W. Immerzeel, L.P.H. Beek, M.F.P. Bierkens, Climate change will affect the Asian water towers, Science 328 (5984) (2010) 1382-1385.

[40] H.J. Jin, Z. Wei, S.L. Wang, Q.H. Yu, L.Z. Lu, Q.B. Wu, et al., Assessment of frozen-ground conditions for engineering geology along the Qinghai-Tibet highway and railway, China, Eng Geol 101 (3-4) (2008) 96-109.
[41] M.Y. Pang, L.X. Zhang, C.B. Wang, G.Y. Liu, Environmental life cycle assessment of a small hydropower plant in China, Int J Life Cycle Assess 20 (6) (2015) 796-806.

[42] W. Suwanit, S.H. Gheewala, Life cycle assessment of mini-hydropower plants in Thailand, Int J Life Cycle Assess 16 (9) (2011) 849-858.

[43] J.S. Ding, J.X. Lin, S.Y. Ma, Qinghai Plateau regional water and electricity-intensive development of the ecological impact analysis section of the river, J Hydroecology 1 (2008) 14-19. [in Chinese].

[44] G. Ardizzon, G. Cavazzini, G. Pavesi, A new generation of small hydro and pumped-hydro power plants: Advances and future challenges, Renew Sustain Energy Rev 31 (2014) 746-761.

[45] X.J. Yao, G.X. Liu, J.L. Zhu, Z.H. Yuan, L. Zhang, Y.Q. Wang, et al., Renewable energy and its power generation technology, Science Press, Beijing, 2010. [in Chinese].

[46] P. Nyima, Brief discussion of the safety management of small hydropower plants in Tibet. Small Hydro, Power 5 (2014) 45-48. [in Chinese].

[47] State Grid Tibet Electric Power Company Limited. Planning of Tibetan state grid during the 12th-Five-Year Plan. Lhasa (in Chinese); 2014.

[48] Q. Wang, H.N. Qiu, Situation and outlook of solar energy utilization in Tibet, China, Renew Sustain Energy Rev 13 (2009) 2181-2186.

[49] D. Zhang, Q.M. Chai, X.L. Zhang, J.K. He, L. Yue, X.F. Dong, et al., Economical assessment of large-scale photovoltaic power development in China, Energy 40 (1) (2012) 370-375.

[50] H.S. Wang, J.C. Nyima, The survey of photovoltaic waste pollution in Qinghai, Qinghai Soc Sci 5 (2007) 58-60. [in Chinese].

[51] H.Y. Luo, Z.Z. Liu, D.J. Luosang, The present situation and future of small hydropower development in Motuo County, Tibet, China Rural Water Hydropower 125 (2009) 158-159. [in Chinese].

[52] G.L. Luo, X.H. Zhang, Universalization of access to modern energy services in Ti betan rural households-Renewable energy's exploitation, utilization, and policy analysis, Renew Sustain Energy Rev 16 (2012) 2373-2380.

[53] Y.G. Kong, Z.G. Kong, Z.Q. Liu, C.M. Wei, G.C. An, Substituting small hydropower for fuel: The practice of China and the sustainable development, Renew Sustain Energy Rev 65 (2016) 978-991.

[54] Y.P. Fang, Y.Q. Wei, Climate change adaptation on the Qinghai-Tibetan Plateau: The importance of solar energy utilization for rural household, Renew Sustain Energy Rev 18 (2013) 508-518. 